\title{
Reliability of Fuel Assembly Effluent Temperatures Under LOCA/LOPA Conditions
}

by

A. D. Sachs

Westinghouse Savannah River Company

Savannah River Site

Aiken, South Carolina 29808

P. M. Garrett

L. A. Wooten

D. L. Bell

DOE Contract No. DE-AC09-89SR18035

This paper was prepared in connection with work done under the above contract number with the U. S. Department of Energy. By acceptance of this paper, the publisher and/or recipient acknowledges the U.S. Government's right to retain a nonexclusive, royalty-free license in and to any copyright covering this paper, along with the right to reproduce and to authorize others to reproduce all or part of the copyrighted paper. 


\section{DISCLAIMER}

This report was prepared as an account of work sponsored by an agency of the United States Government. Neither the United States Government nor any agency thereof, nor any of their employees, make any warranty, express or implied, or assumes any legal liability or responsibility for the accuracy, completeness, or usefulness of any information, apparatus, product, or process disclosed, or represents that its use would not infringe privately owned rights. Reference herein to any specific commercial product, process, or service by trade name, trademark, manufacturer, or otherwise does not necessarily constitute or imply its endorsement, recommendation, or favoring by the United States Government or any agency thereof. The views and opinions of authors expressed herein do not necessarily state or reflect those of the United States Government or any agency thereof. 


\section{DISCLAIMER}

Portions of this document may be illegible in electronic image products. Images are produced from the best available original document. 
Document: WSRC-RP-91-1016

Title: $\quad$ Reliability of Fuel Assembly Effluent Temperatures under LOCA/LOPA Conditions

APPROVALS
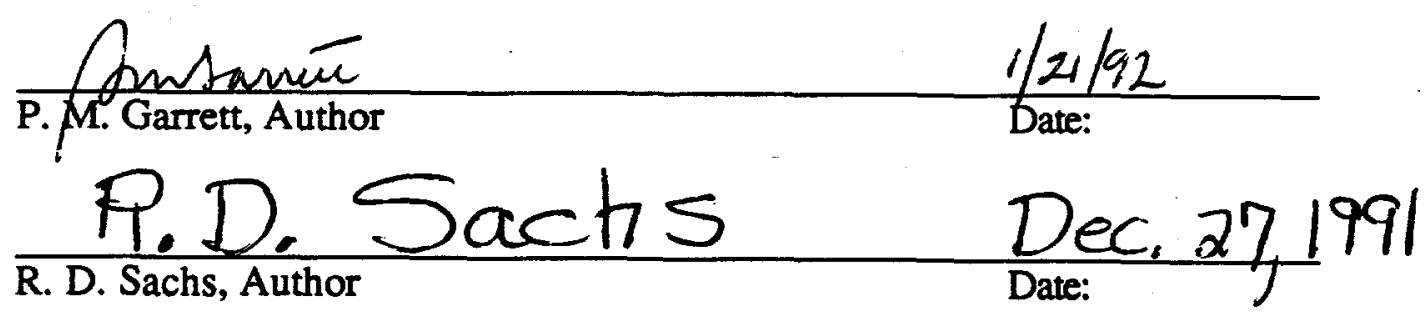

R. D. Sachs, Author
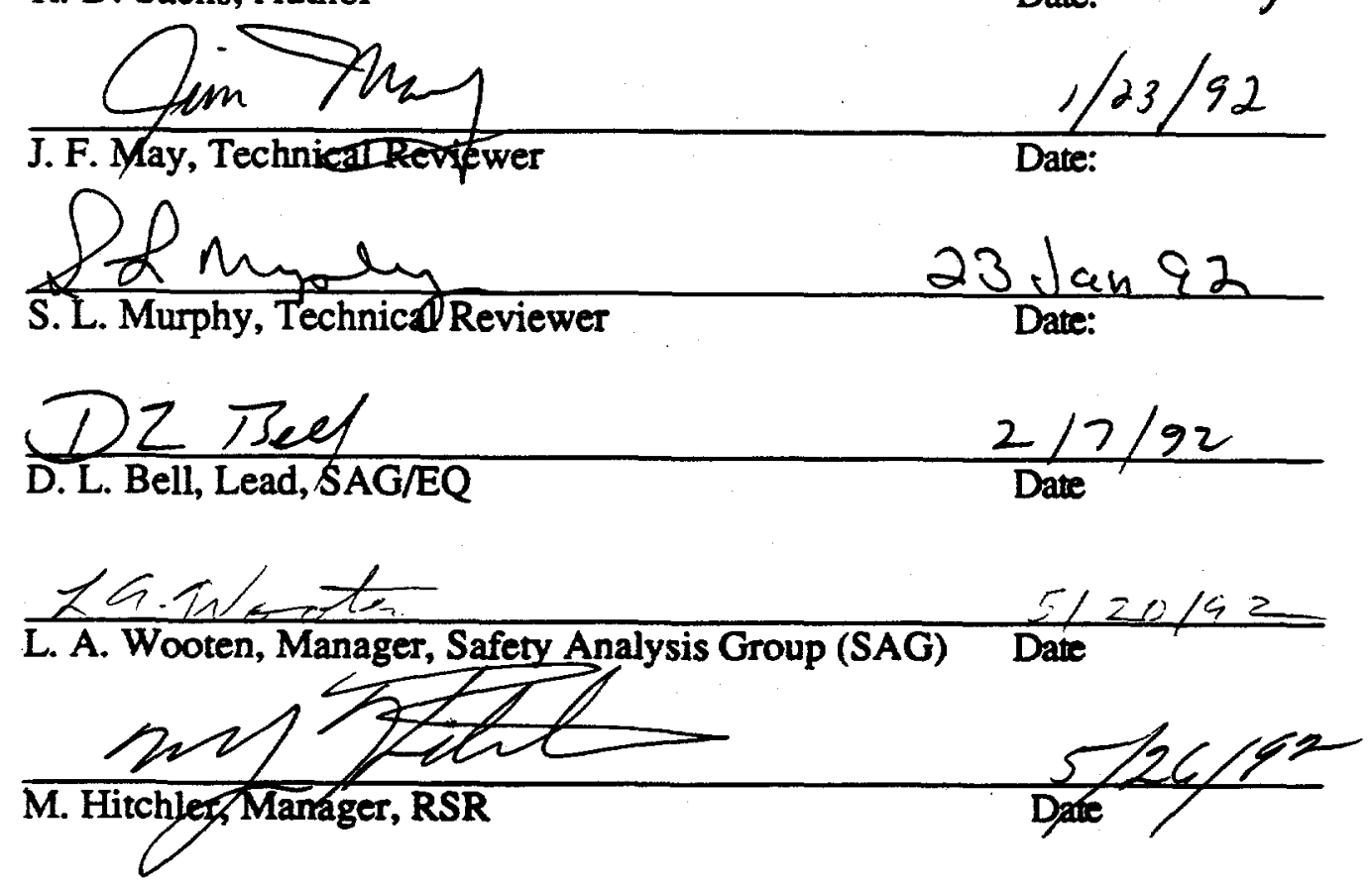


\section{Table of Contents}

\section{Page}

$\begin{array}{lll}1.0 & \text { Introduction } & 1\end{array}$

$2.0 \quad$ Method of Analysis 2

2.1 Assumptions 2

2.2 Actual Process to Determine MP Temperatures 2

2.3 Computer Simulator Process for MP Temperatures 3

$2.4 \quad$ Some Potential J TC Fault Effects $\quad 4$

$2.5 \quad$ Some Potential RTD Fault Effects 4

$\begin{array}{lll}3.0 & \text { Results } & 8\end{array}$

$\begin{array}{lll}4.0 & \text { Conclusions } & 9\end{array}$

$\begin{array}{lll}5.0 & \text { References } & 11\end{array}$

6.0 Appendices

Appexdix A, Input Data 12

Appendix B, Applicable AET Engineering Drawing List 13

Appendix C, Computer Program Listing 14

Appendix D, Computer Program Documentation 17 


\section{List of Tables}

Table A.1-1

Safety Computer SRS RTD Calibration

Page Coefficients

\section{List of Figures}

Figure 2.4-1

Figure 2.4-2

Figure 2.5-1

Figure D.1-1

Figure D.2.1-1

Figure D.2.2-1
Front End Analog Processing Electronics for the Monitor Pin TC.

Simplified Diagram of the MP TC Front End Processing Electronics.

General Flowchart for the Simulator Code

"AETSIMU, BAS".

Monitor Pin Temperatures.

24 


\subsection{INTRODUCTION}

The purpose of this study was to ascertain whether or not the K-Reactor safety computers could calculate primarily false positive, but also false negative, and "on-scale" misleading fuel assembly average effluent temperatures (AETs) due to relatively large temperature changes in or flooding of the $-36^{\prime}$ elevation isothermal box during a LOCA/LOPA. The isothermal box is the common, nonzero degrees Celsius, cold reference junction for all the 2,400 nominal fuel flow channel monitor pin (MP) thermocouples (TC). This study also addressed the failure modes of the TCs and resistance temperature detectors (RTDs) and their associated analog processing electronics due to LOPA flooding, and how the safety computers would react to these failures.

A false positive indication, here temperature, is one that is presented "on-scale" on the Central Control Room (CCR) output indicating device and thus, the indication may appear reasonable or normal, when in fact it is, and should be presented as "off-scale" low. A false negative reading is the inverse of the false positive reading.

The safety and control computers continuously monitor the D2O process water effluent temperatures using type J (iron-constantan) thermocouples mounted inside each of the 2,400 MPs located in the bottom of each flow channel. The safety and control computers monitor/input the analog processed MP millivolt outputs from the four coolant flow channels associated with each fuel assembly, and then computes the average temperature of the the four channels to yield the AET for that one fuel assembly. This process is repeated for all 600 nominal fuel assemblies. The realtime AET information is then used for reactor safety, e.g.,shutdown, and also for real-time reactor control [1].

Six RTDs are attached to the isothermal box to monitor and transmit the actual reference, i.e., cold junction temperature information to the RTD analog and digital processing electronic systems, so that corrections (also called compensations) can be made, within limitation, to the MP TC voltages. This compensation will allow the MP temperatures to be referenced to zero $(0)$ degrees Celsius where the type J TC calibration equations are calibrated and validated.

This study simulated the safety/control computers using the AET calculational process for one monitor pin by calculating a compensated MP temperature value based on a known typical process water MP temperature and a range of isothermal box simulation temperatures.

For this study, the safety computer simulation results will be referred to as MP temperature instead of AET. This is because AET values are the average of four MP TC voltage values from each fuel assembly, whereas the simulations carried out in this work were for a single MP, and hence, are not averaged values. Therefore, to avoid confusion regarding this averaging process, the reader should understand that MP temperature as used herein is a measure of the same parameter, i.e., fuel assembly effluent temperature, as AET.

The safety and control computers receive and process MP TC and RTD voltage values to calculate, utilize and annunciate AETs. The processes performed by both computer systems use essentially the same methodology. However, because the primary purpose of this work was to examine the potential for CCR operators to receive misleading AET indications under LOCA and LOPA conditions, the computer aspects of this study were mostly limited to the safety computer treatment of the TC and RTD voltages. It is anticipated that the results of this work that relate to the safety computers are applicable to the reactor control computers as well.

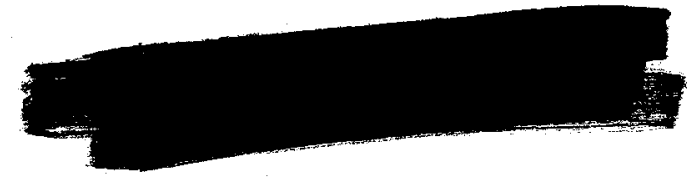




\subsection{METHOD OF ANALYSIS}

\subsection{ASSUMPTIONS}

This section lists the assumptions used in the analysis and the computer simulation code.

2.1.1 The ANSI Standard J thermocouple calibration coefficients are sufficiently accurate to calculate the simulated uncompensated millivolt output from the MP type J thermocouple.

2.1.2 The electrical resistance shunting effects from the terminal strips (TS) to ground associated with the thermocouple and RTD systems are negligible.

2.1.3 The analog front processing electronics for the RTD system is comprised of a Wheatstone Bridge, incorporating the RTD as one leg, and a high input impedance differential voltage amplifier front end, such as an instrumentation amplifier. (The other three legs of the bridge use $100 \mathrm{ohm}$ precision resistors.)

2.1.4 The worst case electrical conductivity of the CWS flood water mixed with ECS polyborate water is $1,000 \mathrm{micromhos} / \mathrm{cm}$.

2.1.5 The front end analog processing electronics for the MP TC and RTD uses a Burr Brown instrumentation amplifier for both the safety and control computers.

\subsection{Actual Process to Determine MP Temperatures}

The K-Reactor safety computers calculate the compensated, or actual, AETs using the data flow diagram (DFD) shown in Fig. D2.1-1 [2].

The MP iron-constantan (Type J) thermocouple (TC) develops an output range of tens of millivolts, over its useful, 0 to 100 degrees Celsius temperature span. The K-Reactor MP process produces an uncompensated potential difference (PD) between the hot and cold (reference) junctions because the cold junction reference temperature is not at zero degrees Celsius. The PD is non-linearly proportional to the temperature difference between the MP hot junction and the isothermal box cold reference temperature (which is not at zero degrees Celsius). The uncompensated J TC millivoltage is then processed with an analog instrumentation amplifier (IA) to produce a full scale voltage output which is compatible with the computer's analog to digital converter (ADC). The amplified TC voltage value is then digitally scaled with other analog reference voltages and processed by the safety computers.

The analog outputs from the RTDs, MV $_{\mathrm{rtd}}$, are analog processed using an IA front end which inputs the output from a Wheatstone Bridge (Assumption 2.1.3) to an ADC. The digital equivalent of the processed RTD voltage is also digitally scaled identically as the TC voltage. Eq. A.1-1 is used by the safety computer compensation process to produce a scaled RTD millivoltage value, $\mathrm{MV}_{\mathrm{RTDJ}}$,which is referenced to a J TC at zero degrees Celsius [2]. 
The digitally scaled TC and compensated RTD voltage values are added to produce a compensated digital voltage value which is a function of actual MP temperature, now referenced to zero degrees Celsius $\left({ }^{\circ} \mathrm{C}\right)$.

The safety computers then use the inverse ANSI Standard J thermocouple equation, i.e., $T_{Z}=$ $\mathrm{f}\left(\mathrm{MV}_{\text {comp }}\right)$, where $\mathrm{T}_{\mathrm{Z}}$ is the temperature (referenced to zero $(\mathrm{Z})$ degrees Celsius), to compute the MP temperature referenced to zero degrees Celsius. The inverse J TC equation immediately follows [3],

$$
\begin{aligned}
& \mathrm{T}_{\text {safetycom }}=0.024377+19.7842 *\left(\mathrm{~V}_{\text {comp }}\right)-0.193689 *\left(\mathrm{~V}_{\text {comp }^{\wedge}}\right) \\
& +0.00775686^{*}\left(\mathrm{~V}_{\text {comp } \left.^{\wedge 3}\right)}\right. \\
& \mathrm{T}_{\mathrm{Z}}=\mathrm{T}_{\text {safetycom }}
\end{aligned}
$$

where

$\mathrm{T}_{\text {safetycom }}$ is the monitor pin temperature (referenced to degrees $\mathrm{C}$ ) as calculated by the safety computers $\left({ }^{\circ} \mathrm{C}\right)$.

$V_{\text {comp }}$ is the the sum of the J TC voltage and the RTD compensated voltage (mv). $V_{\text {comp }}$ represents the TC voltage that would exist if the isothermal box reference temperature was at a temperature of exactly zero (melting ice) degrees Celsius.

\subsection{Computer Simulation Process for MP Temperatures}

Figure D.2.2-1, is the data flow diagram (DFD) of the computer process used to simulate the K-Reactor safety computer process of determining MP temperatures.

The first steps beginning with $T_{\text {rtd }}$ in Fig. D.2.2-1 have been shown to be equivalent to the following RTD millivolt output, referenced to the J TC, according to the following equation [2],

$$
M V_{\text {rtdcomp }}=A+B^{*}\left(T_{\text {ref }}\right)+C^{*}\left(T_{\text {ref } \left.^{\wedge} 2\right)}\right.
$$

where

$\mathrm{MV}_{\mathrm{rtdcomp}}$ is the compensation value generated by a RTD in a Wheatstone Bridge, as a function of the isothermal box reference temperature, which is referenced to zero degrees Celsius (mv).

$\mathrm{A}, \mathrm{B}$, and $\mathrm{C}$ are polynomial curve fit coefficients, which have the following respective values: $-0.000232315,0.050447,0.0000255605\left(\mathrm{mv} /{ }^{\circ} \mathrm{C}\right)$.

It is fortuitous that Equation 2.3-1 was available because the authors were not able to obtain the raw uncompensated SRS RTD calibration equations, i.e., MVrtd, as a function of temperature (referenced to zero degrees Celsius), so that the MV RTDJ equation A.1-1 (used by the safety computers) could not be used. 
The uncompensated J TC millivolt output $\left(\mathrm{MV}_{\mathrm{jtc}}\right)$ as a function of temperature can be calculated using the ANSI millivolt versus temperature calibration equation, which is presented in Eq. A.2-1.

The compensated RTD millivolt output and the uncompensated J TC output are then added to produce a simulated and compensated $J$ TC millivolt output, $V_{\text {comp. The digital scale factors were }}$ not necessary in the simulation because they are constants for both the RTD and the J TC output millivolts.

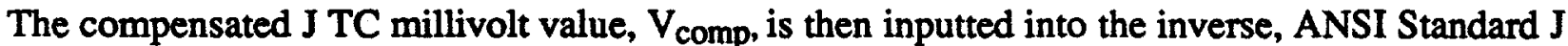
TC temperature versus millivolt polynomial equation (Eq. 2.2-1) to produce the J TC compensated (to zero degrees Celsius) "best-estimate" MP temperature, $\mathrm{T}_{\mathbf{z}}$.

\subsection{Some Potential J TC Fault Effects}

Figure 2.4-1 shows one of the actual front-end electronic diagrams for the control computer MP TC. This study assumed (see Assumption 2.1.5) that the analog IA front end electronics is also used for the safety computers.

Figure 2.4-2 is a simplified circuit diagram for the front-end analog electronic processing circuitry for the the raw J TCs millivolt outputs. The raw J TC millivolt floating output voltage signal is inputted into an (IA). The IA is a low DC drift/noise, differential amplifier which has a low frequency, very high common mode rejection ratio (CMRR), very large input impedance at both of its inputs, and variable voltage gain solid state device $[4,5]$. The IA is specifically designed to accept low level floating differential signals, and its low output impedance, i.e.,voltage output, is compatible with almost all standard off-the-shelf analog electronic devices, such as voltage comparators.

An analytical estimate of the minimum equivalent shunting resistance across the flooded terminal strip (TS) (Fig. 2.4-2), connected to the TC outputs (and its associated front end analog electronics), for a range of flood water conductivities of 100 to $1,000 \mathrm{micromho} / \mathrm{cm}$ was calculated to range from about 1,000 to 10,000 ohms, respectively [6].

The effect of this shunt resistor on the analog processing electronics can be seen by referring to Fig. 2.4-2. The voltage applied to the IA (neglecting the effects of the equivalent shunting resistances to ground from the TS) is equal to the millivoltage division of the floating TC millivoltage, $\mathrm{Vjtc}$, across the TC wire lead resistance and the equivalent shunt resistance presented to the front end of the IA, which has an $80 \mathrm{~K} \mathrm{ohm}$ resistor connected to its floating differential voltage front end. This effect is negligible even with the highest (worst case 1,000 michromho/cm) electrical conductivity water, with its estimated TS shunt resistance of 10,000 ohms [6].

\subsection{Some Potential RTD Fault Effects}

Figure 2.5-1 shows the simplified assumed (see Assumption 2.1.3) circuit diagram for the front end analog electronic processing of the raw RTD voltages, which produces the actual voltage signals for the isothermal (TC cold junction) reference box. The RTD was assumed to be incorporated into a Wheatstone Bridge. As the temperature increases, the RTD resistance (100 ohms nominal) non-linearly increases [7]. This causes the bridge output differential millivoltage to increase, which in turn is buffered and amplified by the IA, or an equivalent processing electronics, to produce a voltage output, with respect to analog ground, i.e., zero volts, compatible with an $A D C$ input voltage span.

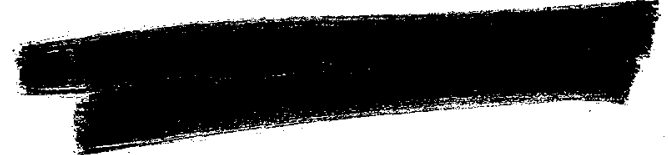




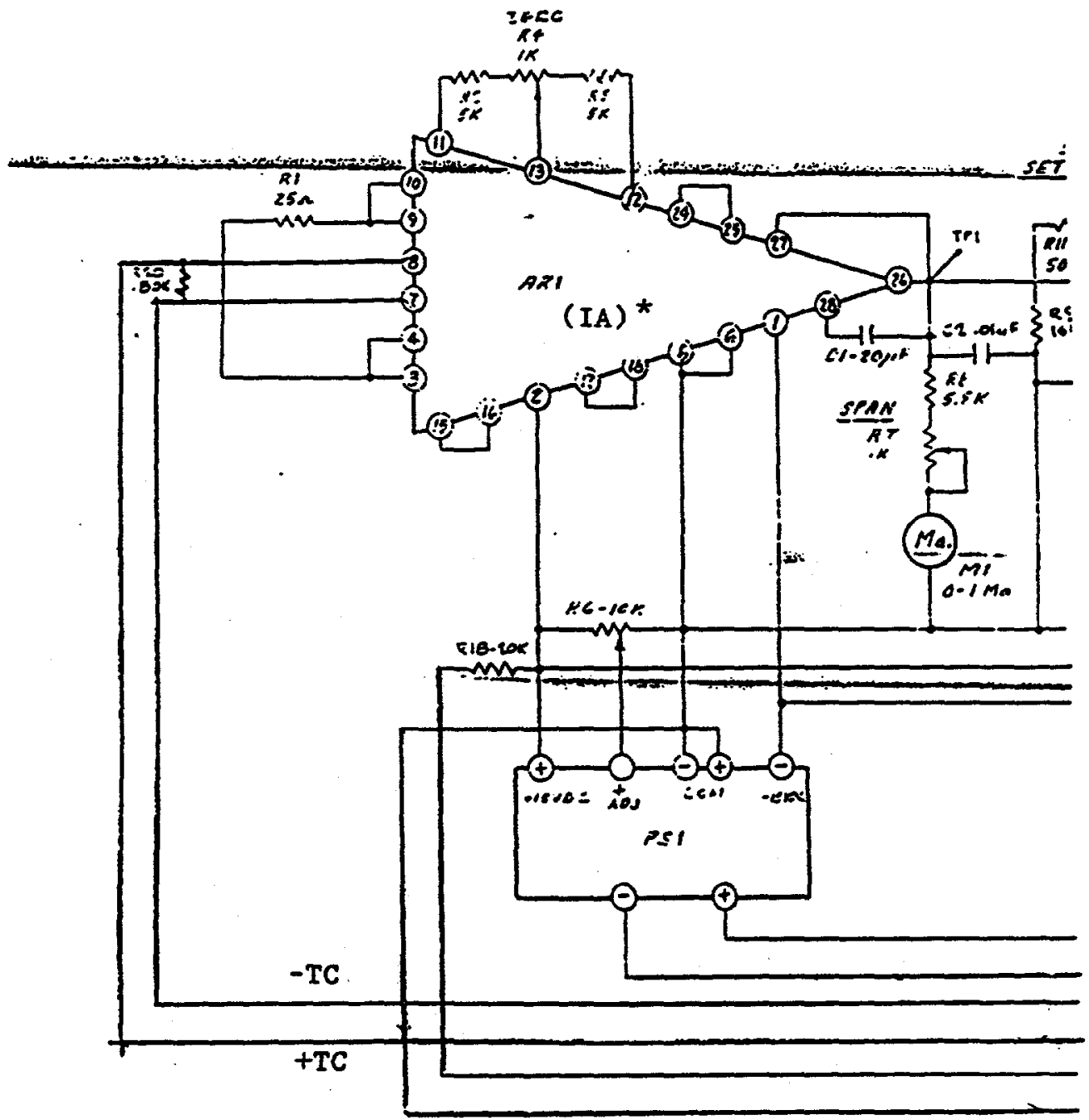

* IA is a Burr Brown 3620L Instrumentation Amplifier

Figure 2.4-1. Front End Analog Processing Electronics For the Monitor Pin (MP) TC. 


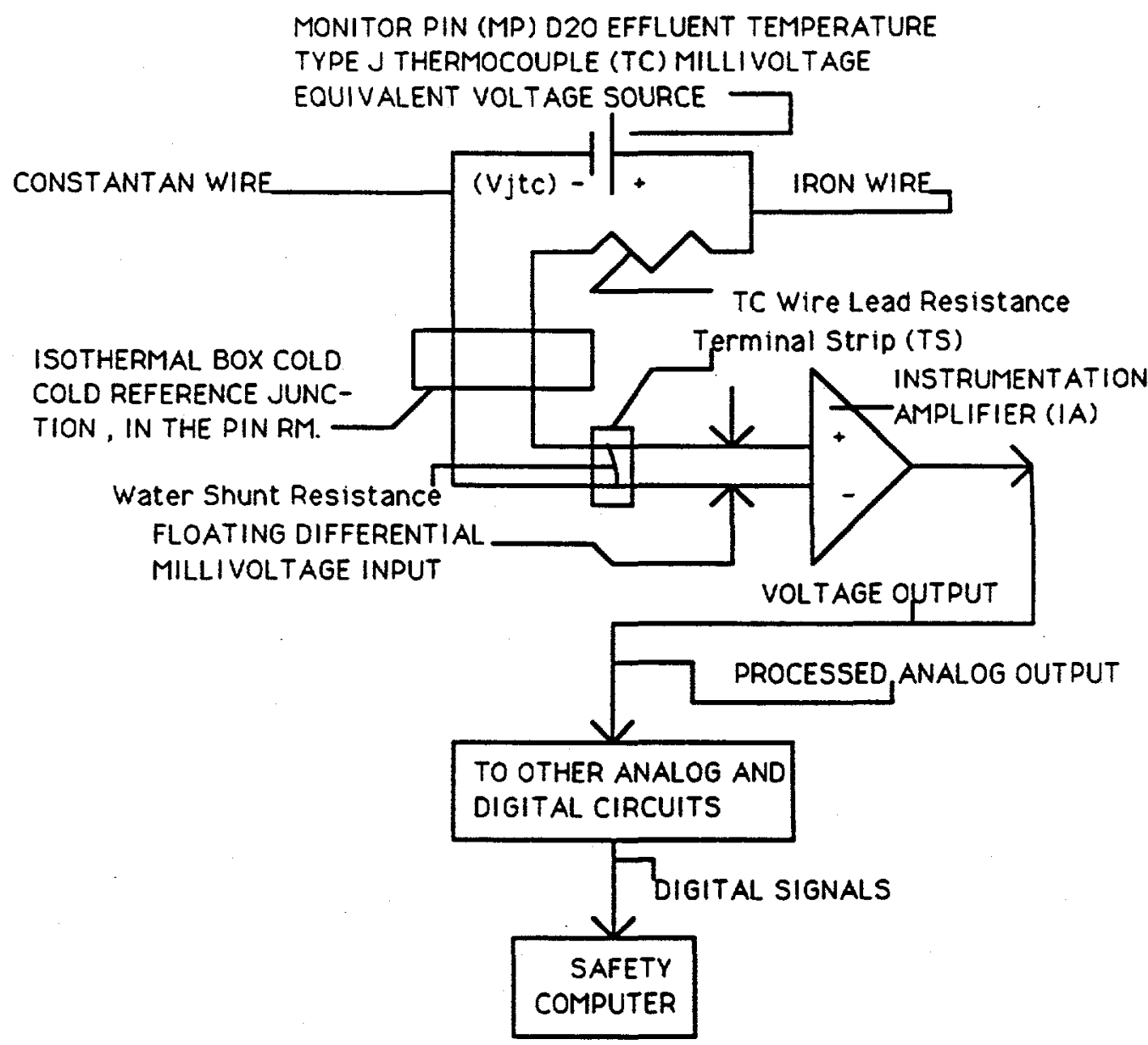

NOTES :

1. Vjtc is the tens of millivolts outputted by the the JTC

2. The J TC wire lead resistance is approx. 0.1 ohms

Figure 2.4-2. Simplified Diagram of the MP TC Front End Processing Electronics. 


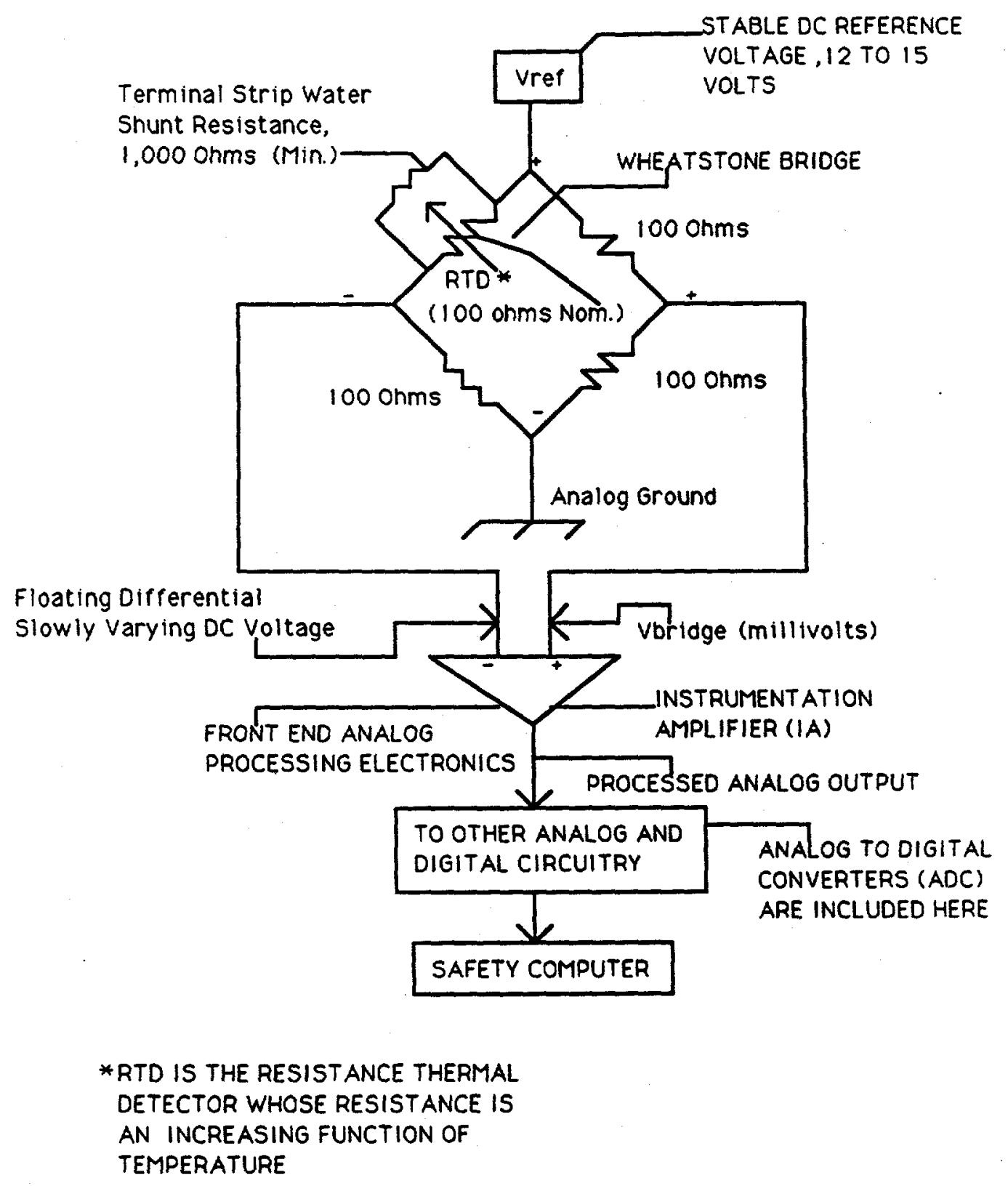

Figure 2.5-1. Simplified Front End Analog Electronics For the RTD sensor. 
The values of equivalent shunting resistance across the flooded terminal strip (and neglecting the other shunt resistances, see Assumption 2.1-2), will cause the equivalent resistance in the Wheatstone Bridge to decrease-refer to Fig. 2.5-1. This decrease in resistance will unbalance the bridge circuit [5].

The equation for the instantaneous and slowly varying floating DC millivoltage output of the Wheatstone Bridge can be shown to be,

$$
\begin{aligned}
V_{\text {bridge }} & =V_{\text {Ref }} / 2-\left(V_{\text {Ref }} * 100\right) /\left(R_{\text {rtdeq }}+100\right) \\
& =V_{\text {Ref }} *\left(0.5-100 /\left(R_{\text {rtdeq }}+100\right)\right)
\end{aligned}
$$

where

$\mathrm{V}_{\text {bridge }}$ is the bridge millivoltage output which is inputted into the instrumentation amplifier (IA) (mv).

$V_{R e f}$ is the stable reference $D C$ voltage applied across the bridge circuit $(v) . V_{R e f}$ typically ranges from $+12 v$ to $+15 v$, with respect to analog ground.

100 is the assumed nominal resistance of the RTD, and is also the precision resistance values of other three legs of the bridge (ohms).

$\mathbf{R}_{\mathrm{rtdeq}}$ is the parallel equivalent resistance of $\mathbf{R}_{\mathrm{rdd}}$ and the shunt resistance given by ( $\mathrm{R}_{\mathrm{rtd}}$ )(shunt resistance)/(Rrtd + shunt resistance) (ohms). See Figure 2.5-1.

If $R_{r t d}$ is exactly equal to 100 ohms, then the bridge output voltage will be exactly, or very close to, zero volts [7]. Because the equivalent $R_{\mathrm{rtd}}$, i.e., the parallel combination of $R_{\mathrm{rtd}}$ and the water shunt resistance is less than $100 \mathrm{ohms}$ (Fig. 2.5-1), then simple inequality theory operating on

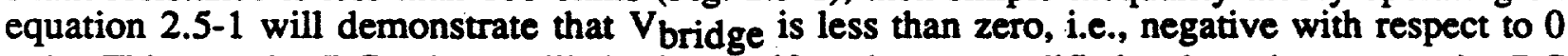
volts. This negative $D C$ voltage will also be manifested as an amplified and maximum negative DC voltage at the output of the IA.

The safety computers will detect and process the negative compensation voltage, $\mathrm{MV}_{\mathrm{RTDJ}}$, to compensate $\mathrm{MV}_{\mathrm{jtc}}$ to yield the MP temperature to determine if this MP temperature is within the range of 4 to $175^{\circ}$ Celsius [1].

\subsection{RESULTS}

This section lists the results of the computer isothermal box temperature variation simulation (3.1), and also the flooding effects (3.2) on the TC and RTD and their associated front end analog processing electronics.

\subsection{Simulation of Potential False Positive/Negative MP Temperature Values}

Computer simulations of the compensated MP temperature calculational process performed by the 
This simulation followed the methodology described in Section 2.3 using Equation A.2-1 to calculate the uncompensated J TC millivolt output, $\mathrm{MV}_{\mathrm{jtc}}$, as a function of temperature, and the RTD compensation millivolt output, $\mathrm{MV}_{\mathrm{rtdcomp}}$, as a function of the isothermal box reference temperature using Eq. 2.3-1. The sum of the values of these two equations, $V_{\text {comp, were then }}$ input to the inverse ANSI Standard J TC relationship given in Eq. 2.2-1 to yield the compensated MP temperatures, $\mathrm{Tz}$, over a $40^{\circ} \mathrm{C}$ range of isothermal box reference temperatures.

The results of the simulation calculations found, that over an isothermal box temperature range from 20 to $60^{\circ} \mathrm{C}$, the estimated MP temperature varied from 88.85 to 88.70 , respectively, compared to a known actual MP temperature of $90.0^{\circ} \mathrm{C}$. The lowest MP temperature value found was 88.47 at approximately $40{ }^{\circ} \mathrm{C}$. This shows that large variations in isothermal box temperatures yield small calculated variations in compensated MP temperatures.

\subsection{Effects of Flooded TS Associated with the TC and RTD Temperature Systems}

As discussed in Section 2.4, flooding the TC terminal strips produces negligible changes to the voltages, $\mathrm{MV}_{\mathrm{jtc}}$, input to its associated analog electronic processing circuitry regardless of the flood water conductivity.

However, as discussed in Section 2.5, substantial changes result in the RTD analog processed output voltages, $\mathbf{M V}_{\mathrm{rtd}}$, when the $\mathrm{RTD}$ terminal strips are flooded. Over a range from 100 to 1,000 micromho/cm of shunting CWS flood water, which corresponds to a range from 1,000 to $10,000 \mathrm{ohms}$ [6], respectively, the values of $M V_{\text {rtd }}$ ranged from -0.357 to -0.0373 volts, respectively, using Eq. 2.5-1, where Vref is assumed to be +15 vDC. Assuming a minimal closed loop voltage gain of the instrumentation amplifier of 100 , the $-0.037 \mathrm{v}$ value yieids a calculated MP temperature of $-1.00^{\circ} \mathrm{C}$ at an isothermal box temperature of $20^{\circ} \mathrm{C}$ using the simulator code. As

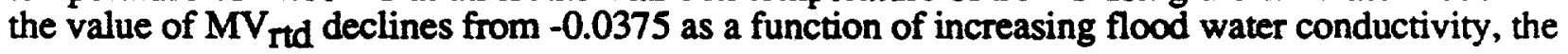
estimated MP temperature becomes more negative. As the isothermal box reference temperature increases above $20^{\circ} \mathrm{C}$, the estimated MP temperature becomes more negative for the same flood water conductivity.

Because the safety computer checks the calculated compensated MP temperature against an acceptance criterion temperature range of 4 to $175^{\circ} \mathrm{C}$ using a reasonableness test (minimum value, maximum value, maximum change in one minute and maximum allowable sensor millivolt difference). The negative temperature values calculated by the safety computer will be rejected and reported as an offline alarm [8].

\subsection{CONCLUSIONS}

\subsection{Potential False Positive/Negative Safety Computer MP Temperatures}

Computer simulations verified that the safety computers accurately compensate for relatively large changes in isothermal box temperatures. No positive or negative false temperatures are produced in the compensation process for the MP J TC as a function of isothermal box reference temperature. 


\subsection{Effects of Flooding the TC and RTD TS on the Indicated MP Temperature.}

Based on flood water conductivity ranging from 100 to 1,000 micromho/cm, a flooded RTD terminal strip will yield a negative voltage out of the RTD front end processing analog electronics. This negative voltage will be detected, processed and annunciated by the safety computers as an error message.

Wetting of the RTDs is only expected to occur if the isothermal box, which is located in the $-40^{\prime}$ elevation Pin Room, becomes flooded because wiring penetrations that could lead to internal wetting of the isothermal box are sealed to protect against sprays. Hence, the only DBA that is expected to cause wetting of the RTDs is a LOPA, and this would probably occur within the first eight to ten minutes of the event. Because ECS throttling is no longer a CCR procedural step in responding to a LOPA, per ACC Procedure MC-6, reliable fuel assembly effluent temperature readings to guide throttling operations are no longer required. However, it is reassuring to know as a result of this study that wetting of the RTDs during a LOPA would not lead to false fuel effluent temperature indications that would cause the operators to change the accident response configuration of the plant in such a way that the plant condition would be degraded even further.

Even though the RTDs should not be wetted during a LOCA, it is certainly possible for the sprayproof sealings of this isothermal box penetrations to leak, and thereby cause failure of the RTDs. Because ECS throttling during a LOCA is such a crucial aspect of the accident management response to a LOCA, false fuel assembly effluent temperature indications could cause the CCR operators to be misled during their ECS throttling procedure, and a a consequence, create a more sever accident condition than would otherwise exist. This possibility will be avoided as a result of the safety computers reporting an error message if the isothermal box internal become wetted as opposed to reporting false temperatures. 


\section{REFERENCES}

1. Little, J.W., "OS Center Section Nuclear Console Qualification Card Safety Computers," WSRC document CS-GEN- IR-Consol-0102-OJT, May 15, 1990.

2. Finley, D.A., "Temperature Setpoints and Conversion Equations, " WSRC Reactor Technology Report RTR-1630, Aug. 18, 1977.

3. "Standard Temperature-Electromotive Force (EMF) Tables for Thermocouples," ASTM E230-72, Approved, April 2, 1973 by American National Standards Institute, ANSI, for ANS C96, Feb. 1973.

4. Sachs, R.D., et al., "Low-Noise Audio Amplifiers and Preamplifier for Use with Intrinsic Thermocouples," Los Alamos National Laboratory (LANL), LANL report LA-7562 (UC37), Mar. 1979.

5. Burr-Brown (BB) Customer Service Center, "INA101 Very-High Accuracy Instrumentation Amplifier, " BB Product Data Sheet PDS-454H, Burr Brown Corporation, Tucson, Arizona, Aug. 1988.

6. McCulloch, R., Private Communication Concerning Thermocouple Technology, Delta M Corp., Oak Ridge, Tenn., Oct. 2, 1991.

7. Larsen, J., Selected pages from TE Data Book on RTD Technology, TE Technical Reference K-77 Manual, Thermo Electric (TE) Corp., Atlanta, Ga., Sept. 1991.

8. Safety Computer Abstract SC-4, TEST, Rev 2.

9 Maddox, J., "Safety Computer RTD (Calibration) Coefficients, " WSRC Reactor Engineering Data Sheet, Sept., 1991. 


\subsection{APPENDICES}

\section{APPENDIX A. Input Data}

This appendix contains and references the input data that were used in the circuit analysis and the computer code MP temperature simulator.

\section{A.1 Resistance Temperature Detector (RTD) Calibration Data}

The K-Reactor RTD safety computer calibration data were obtained from the SRS Reactor Engineering Department [9]. Table A.1-1 gives these calibration data for four, of the six, RTDs which are located in the isothermal box and used by the two safety computers. This table lists the polynomial coefficients for the polynomial curve fit of compensated RTD millivolts vs raw RTD millivolts, with respect to the junction thermocouples at zero degrees Celsius.

The polynomial has the form [2],

$$
\mathrm{MV}_{\mathrm{RTDJ}}=\mathrm{A}+\mathrm{B}^{*}\left(\mathrm{MV}_{\mathrm{rtd}}\right)+\mathrm{C}^{*}\left(\mathrm{MV}_{\mathrm{rtd}}{ }^{\wedge}\right)
$$

where

$M V_{R T D J}$ is the compensated millivolt $\left(M V_{\mathrm{rtd}}\right)$ output of the RTD, with respect to the type $J$ (iron-constantan) thermocouple, and referenced to zero degrees Celsius. MV $R$ TDJ is a safety computer calculated value (mv).

A, B, and C are the polynomial curve fit coefficients (Table A.1-1 for four RTDs) obtained from the SRS raw RTD and J TC calibration data (dimensionless).

$M V_{\text {rtd }}$ is the raw uncompensated millivolt output from the RTDs, with respect to zero degrees Celsius. The analog amplified and processed $M V_{\text {rtd }}$ is inputted into the safety computer analog to digital converter (ADCs) (mv).

$\wedge$ means raised to the power of (here 2 ) (dimensionless). 


\section{TABLE A.1-1}

\section{SAFETY COMPUTERS SRS RTD CALIBRATION COEFFICIENTS}

\begin{tabular}{|l|l|l|l|}
\hline RTD Number & Coefficient $\mathrm{A}^{\mathrm{b}}$ & Coefficient B & Coefficient C \\
\hline ISO1, $^{\mathrm{a}}$ & -0.05855 & 0.50215 & 0.002467 \\
\hline ISO2,1 & -0.04166 & 0.50433 & 0.0024865 \\
\hline ISO1,2 & -0.05759 & 0.50216 & 0.002467 \\
\hline ISO2,2 & -0.04287 & 0.50432 & 0.0024865 \\
\hline
\end{tabular}

a The one (1) and the two (2), after the comma, denotes used by safety computer numbered one and two.

b A, B, and C coefficients, from Ref. 2, are used in Eq. A.1-1.

\section{A.2 Type J (Iron-Constantan) Thermocouple Calibration Data}

The type J (iron-constantan) ANSI Standard polynomial curve fit equation is given by [3],

$$
M V_{j t c}=a_{0}+a_{1} *(T)+a_{2} *\left(T^{\wedge} 2\right)+a_{3} *\left(T^{\wedge} 3\right)
$$

where

$\mathrm{MV}_{\mathrm{jtc}}$ is the raw millivolt output of the type J monitor pin (MP) D2O effluent thermocouple (TC), with respect to 0 degrees Celsius, and produced at a temperature (T) (mv).

$a_{0}, a_{1}, a_{2}$, and $a_{3}$ are the coefficients of the ANSI standard polynomial best curve fit (millivolt/(degree C) (mv/ $\left./{ }^{\circ} \mathrm{C}\right)$, and have the respective values of: 0,5.0372753027E-2, 3.0425491284E-5, and -8.5669750464E-8. E means an exponent of 10.

$\mathrm{T}$ is the J TC temperature; with respect to zero (0) degrees (melting ice) Celsius, reference cold junction $\left({ }^{\circ} \mathrm{C}\right)$.

\section{APPENDIX B. Applicable AET Engineering Drawing List}

This appendix lists the applicable SRS engineering drawings used in this study.

A. SRS Electronic drawings-

1. $55-1-4409$

2. $55-1-4410$

B. SRS Isothermal Box drawings- 
1. S5-1-2445

2. $55-1-4367$

3. $55-1-4404$

4. $S 5-1-5406$

5. S5-1-6221

6. $55-1-10030$

7. W114951

8. W133684

9. W141957

\section{APPENDIX C. Computer Program Listing}

This section lists the QUICKBASIC computer language code, filename, AETSIMU.BAS, which simulates the entire process used to determine the temperature for one MP type J TC.

\section{QUICKBASIC Computer program "AETSIMU.BAS"}

REM This program is used to simulate the effects of the ISOTHERMAL BOX REM temperature changes on the average effluent temperature (AET) for the REM CCR safety and control computers. We are investigating if false positive REM or false negative readings can occur--particularily before SCRAM can occur. REM False readings due to the air/water temperature changes from a LOCA or LOPA. REM This QUICKBASIC code is contained in C: BAASICIQBASICAETSIMUL.BAS.

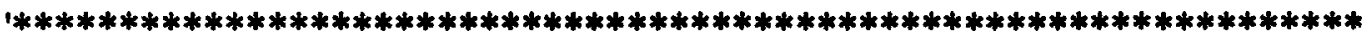

This is the main program for the simulation study of the monitor pin (MP) average effluent temperature (AET) of the exiting D2O near the bottom of the Rx tank core.

This next section defines the variables/arrays that are used in this simulation A, B, C are the RTD SRS obtained calibration coefficients for the four RTDs.

' $I$ is the index for the total number of isothermal box simulation temperatures

'.$J$ is the global index pointer for the RTD calibration input data.

' JRTD (= J) is the RTDCAL subroutine index pointer to the proper SRS calibration coefficients

' Tmp is the constant (for a short time interval) monitor pin (MP) D2O effluent temperature (Celsius).

'Tref is the varying isothermal box (reference junction) known simulation temperatures.

' Tsafetycom is the safety computer calculated temperature from the compensated millivolts.

' $V_{\text {bridge }}$ is the millivolt output of the isothermal box RTD---with respect to zero degrees C. 
'Deltatref is the increment for the Tref isothermal box reference temperature.

' Tisot(105) is the array of the 105 isothermal box temperatures.

'MVMPUC $(105,5)$ is the I, J array of the MP TC uncompensated millivolts for the MP.

'MVMPCOM $(105,5)$ is the I,J array of the MP TC compensated millivolts for the MP.

'MVRTD $(105,5)$ is the $I, J$ array of millivolts (mv) for the RTDs, referenced to zero degrees C.

' Vcomp is the temperature compensated (comp) millivolt number used by the control/safety computers.

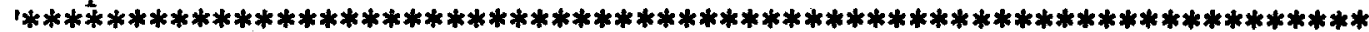

$1 * * * * * * * * * * * * * * * * * * * * * * * * * * * * * * * * * * * * * * * * * * * * * * * * * * * * * * * * * * * * * * * * * * *$

'Beginning of the main program which contains all the subroutine calls.

' MAIN:

DIM MVMPUC(105, 5), MVMPCOM(105, 5), Tisot(105), MVRTD(6000) 'Dimension statement

TMPIN $=90^{\prime}$ constant monitor pin temperature (Celsius) [194 degrees F].

Tref $=20^{\prime}$ Initial varying isothermal box temperature

Deltatref $=.5$

FOR I $=1$ TO 80

DELTATMP $=90$ - Tref Calculate the temp. difference across MP TC.

GOSUB MONPNTC ' Read monitor pin TC millivolts

GOSUB RTDTMP ' Calculate RTD compensated (to J TC) millivolts.

$\mathrm{V}=\mathrm{Vmp}+\mathrm{Vref}$

$\mathrm{Vcomp}=\mathrm{V}$

GOSUB CONTROL ' Calculate the MP voltage using K Rx Safety Computer.

PRINT "Tmp, Tisothermal, Tsafetycom", TMPIN, Tref, Tsafetycom

FOR $\mathrm{JJ}=1$ TO 500 ' Build in time delay loop to read the output

NEXT JJ

Tref $=$ Tref + Deltatref

NEXT I ' End of the FOR-NEXT LOOP

STOP

END ' Physical end of the MAIN program.

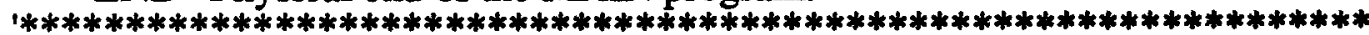

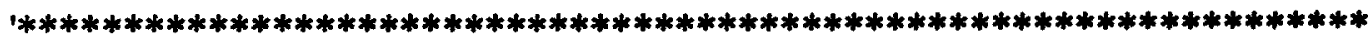

MONPNTC:

' SUBROUTINE MONPNTC(Tmp, Vmp) 
'This subroutine calculates the uncompensated (UC) millivolts for the monitor pin (MP) TC. ' for a known/fixed average monitor pin temperature. The monitor pin TC uses

' an iron-constantan (Type J) TC.

Tmp = DELTATMP

$\mathrm{Vmp}=.0503727 *(\mathrm{Tmp})+3.04259 \mathrm{E}-05 *(\mathrm{Tmp}) \wedge 2-8.566975 \mathrm{E}-08 *(\mathrm{Tmp}) \wedge 3$

RETURN' This is the physical end of this subroutine.

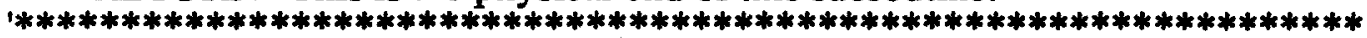

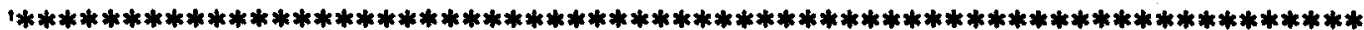

RTDTMP:

- SUBROUTINE RTDTMP(Tref, Vref)

' Subroutine calculates the millivolt output of the RTD reference temperature, with respect to zero ' for the isothermal box---for a known isothermal box reference SIMULATION temperature. Output MV is respect to zero C.

$$
\begin{aligned}
& A=-.000232315 \# \\
& B=.050447 \\
& C=.0000255605 \#
\end{aligned}
$$

$\operatorname{Vref}=A+B *\left(\operatorname{Tref}^{\wedge} 1\right)+C^{*}\left(\operatorname{Tref}^{\wedge} 2\right)$

RETURN ' This is the physical end of this subroutine

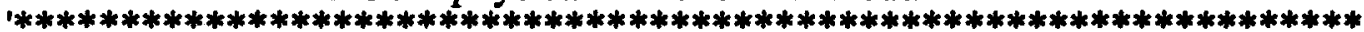

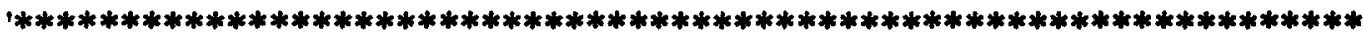

CONTROL:

- SUBROUTINE CONTROL(Vcomp, Tcontr)

' This subroutine calculates the (MP) temperature as a function of compensated

' millivolts, in a manner PRECISELY as done in the $\mathrm{K}$ Reactor Control/Safety computers.

Tsafetycom $=.024377+19.7842 *$ Vcomp $-.193689 *\left(\right.$ Vcomp $^{\wedge} \wedge 2+.00775686 \# *$ (Vcomp) ^ 3

RETURN' This is the end of this subroutine

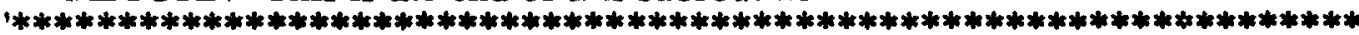

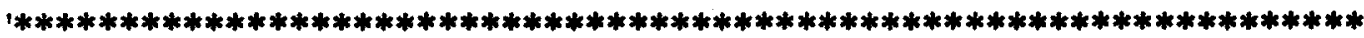

RTDCALINPUT:

- $\quad$ SUBROUTINE RTDCAL (JRTD, A, B, C) ' This subroutine is not needed, but could be used in the future.

' Subroutine where the SRS RTD Calibration Coefficients Reside

' The next statement branches to the proper physical location to pick up the proper RTD

' SRS calibration coefficients, for the four RTDs [obtained from Judy Maddox Reactor 
Engineering]. index

ON JRTD GOTO ISO11, ISO21, ISO12, ISO22 ' JRTD is the RTD calibration coefficient

ISO11:

$A=-.05855$

$\mathrm{B}=.50215$

$\mathrm{C}=.002467$

GOTO THRU ' THRU is a transfer label.

ISO21:

$\mathrm{A}=-.04166$

$\mathrm{B}=.50433$

$\mathrm{C}=.0024865 \#$

GOTO THRU

ISO12:

$A=-.05759$

$\mathrm{B}=.50216$

$\mathrm{C}=.002467$

GOTO THRU

ISO22:

$$
\begin{aligned}
& \mathrm{A}=-.04287 \\
& \mathrm{~B}=.50432 \\
& \mathrm{C}=.0024865
\end{aligned}
$$

THRU: ' TRANSFER TO THIS LABEL.

RETURN ' END OF THE INPUT RTD CALIBRATION SUBROUTINE.

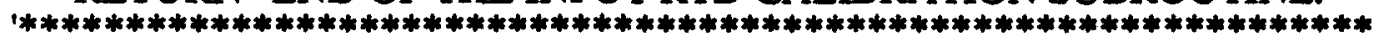

\section{APPENDIX D. Computer Program Documentation}

This appendix lists the general flowchart (D.1) for the simulator code AETSIMU.BAS, and also lists (D.2) the data flow diagrams DFDs for the actual and simulated MP temperature determination process.

\section{D.1 General Flowchart For the Simulator Code AETSIMU.BAS}

The general flowchart, Fig. D.1-1, for the simulator code AETSIMU.BAS immediately follows. Note that the code itself actually has one more subroutine (RTDCAL) than shown in the flowchart. Subroutine RTDCAL can be used in the future if the raw RTD calibration data, i.e., millivolt vs. isothermal temperature, is acquired from SRS personnel. Subroutine RTDCAL computes the RTD millivolt value as referred to a J TC. Subroutine RTDCAL would require: 1) a RTD raw calibration data subroutine, or 2) actual RTD millivolt output as a function of temperature, in order to function properly. 


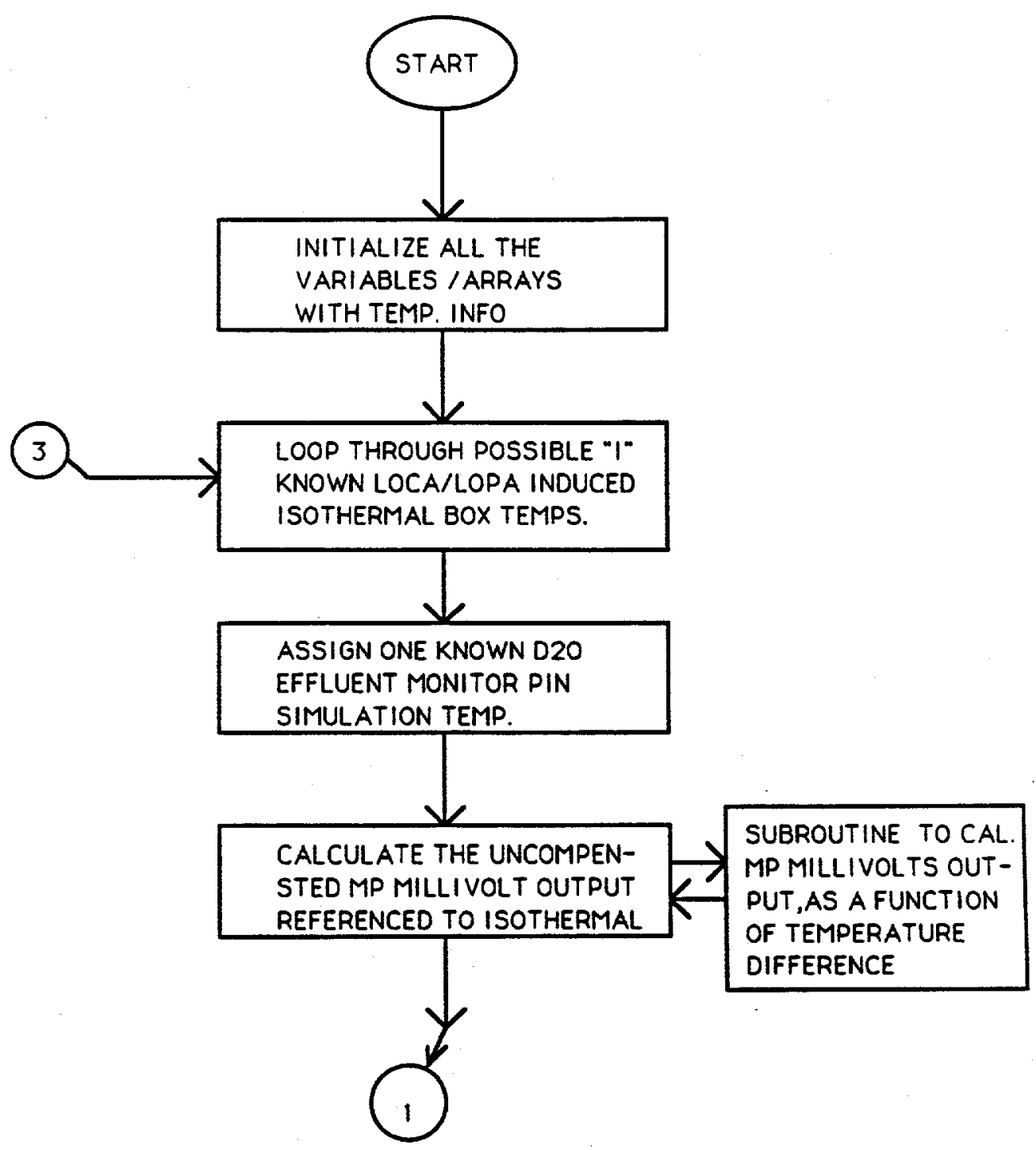

Figure D.1-1. General Flowchart For the Simulator Code "AETSIMU.BAS". 


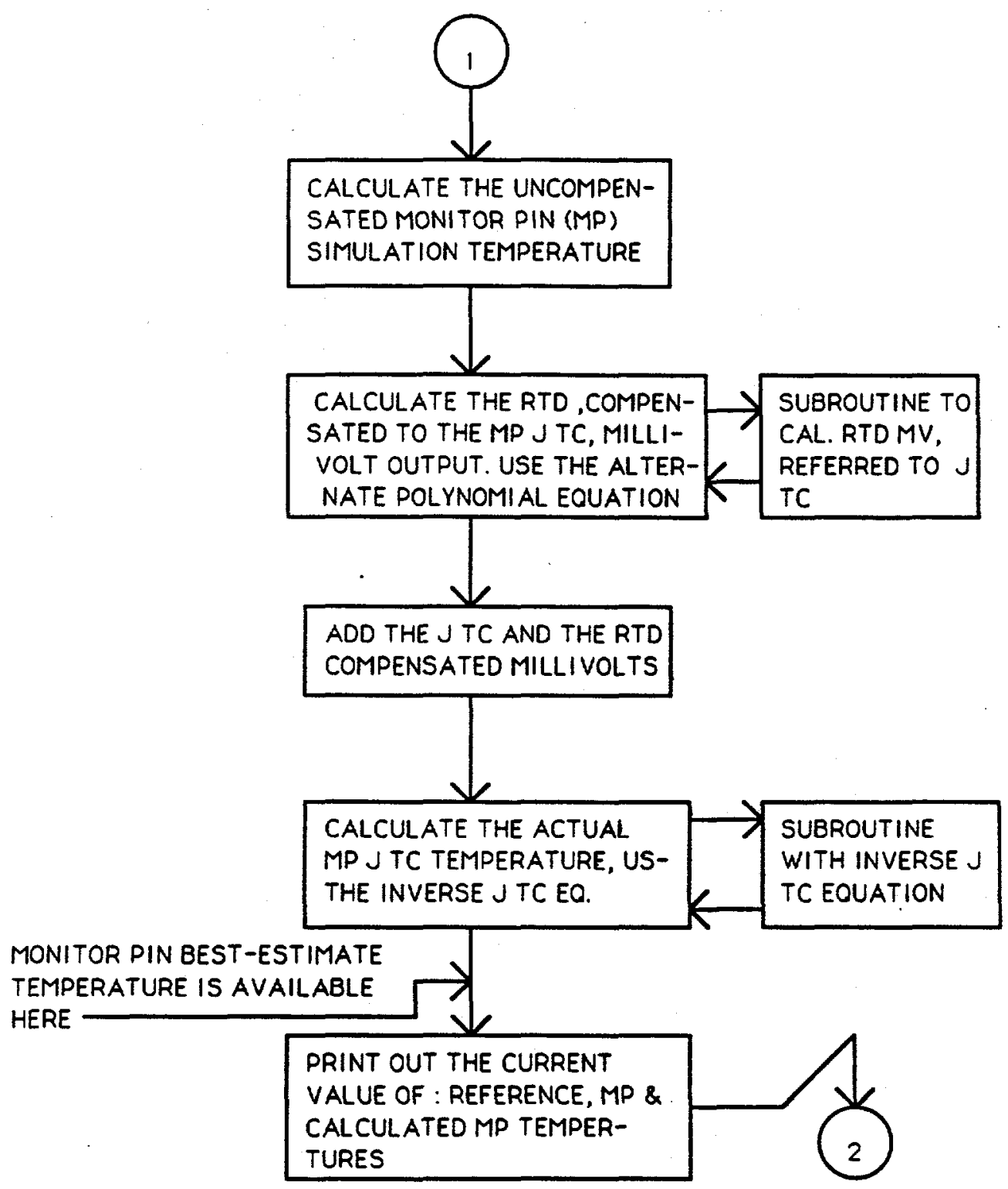

Figure D.1-1. General Flowchart For the Simulator Code

"AETSIMU.BAS" (Continued). 


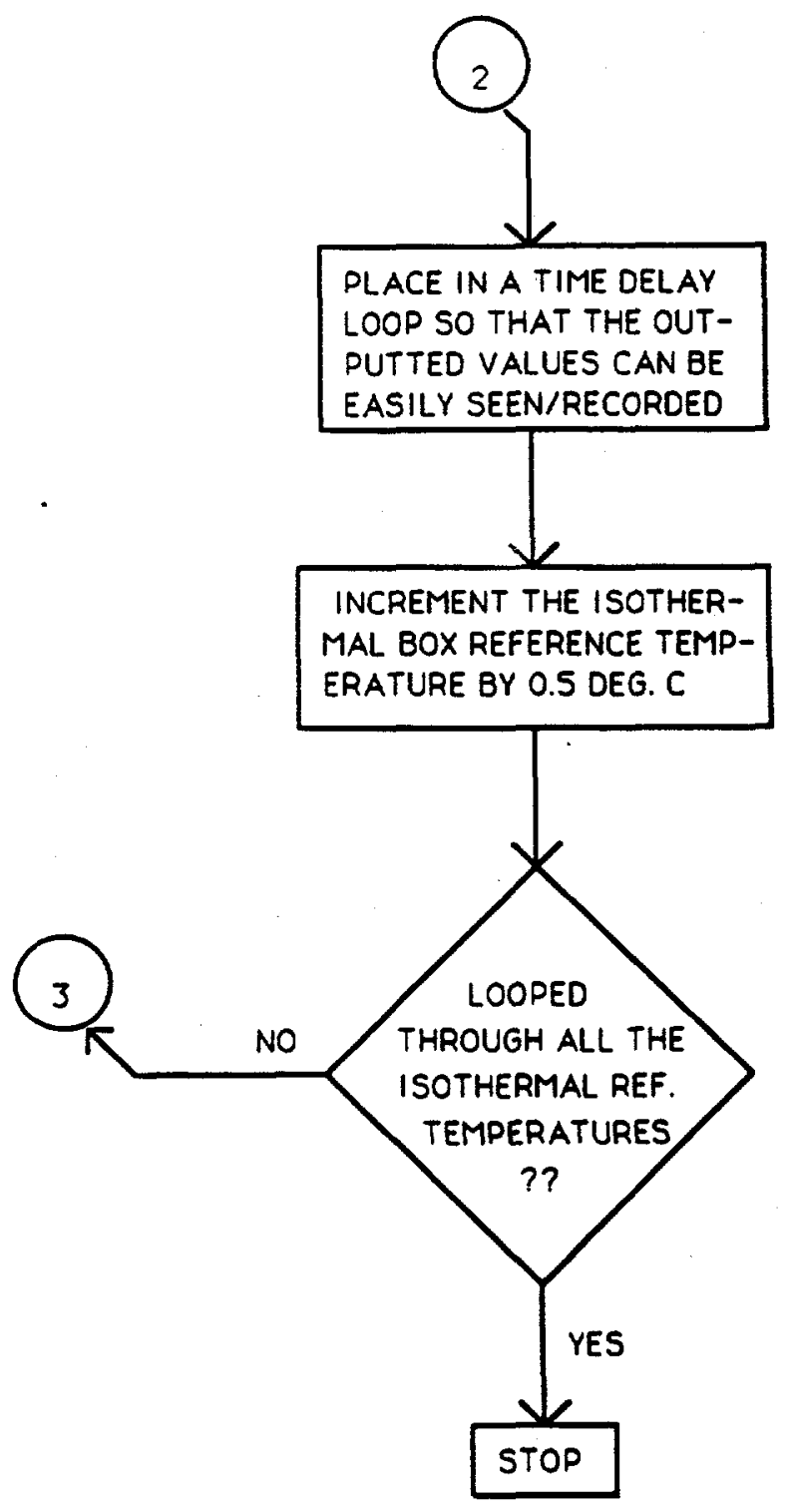

Figure D.1-1. General Flowchart For the Simulator Code "AETSIMUU.BAS" (Continued). 


\section{D.2 Data Flow Diagrams (DFDs) For The Actual and Simulated MP D20 Effluent Temperature Process}

The data flow diagrams (DFD) for the $\mathrm{K}$-Reactor monitor pin D2O effluent temperature determination process are shown in the following pages. Fig. D.2.1-1 is the DFD depicting the actual K- Reactor process by which the MP D2O effluent temperature is obtained. Fig. D.2.2-1 is the DFD illustrating the process in which the MP effluent temperatures were computer simulated.

\section{D.2.1 Data Flow Diagram (DFD) For The Actual Process To Determine The MP Effluent Temperature}

The DFD for the actual process to determine the MP effluent temperature immediately follows.

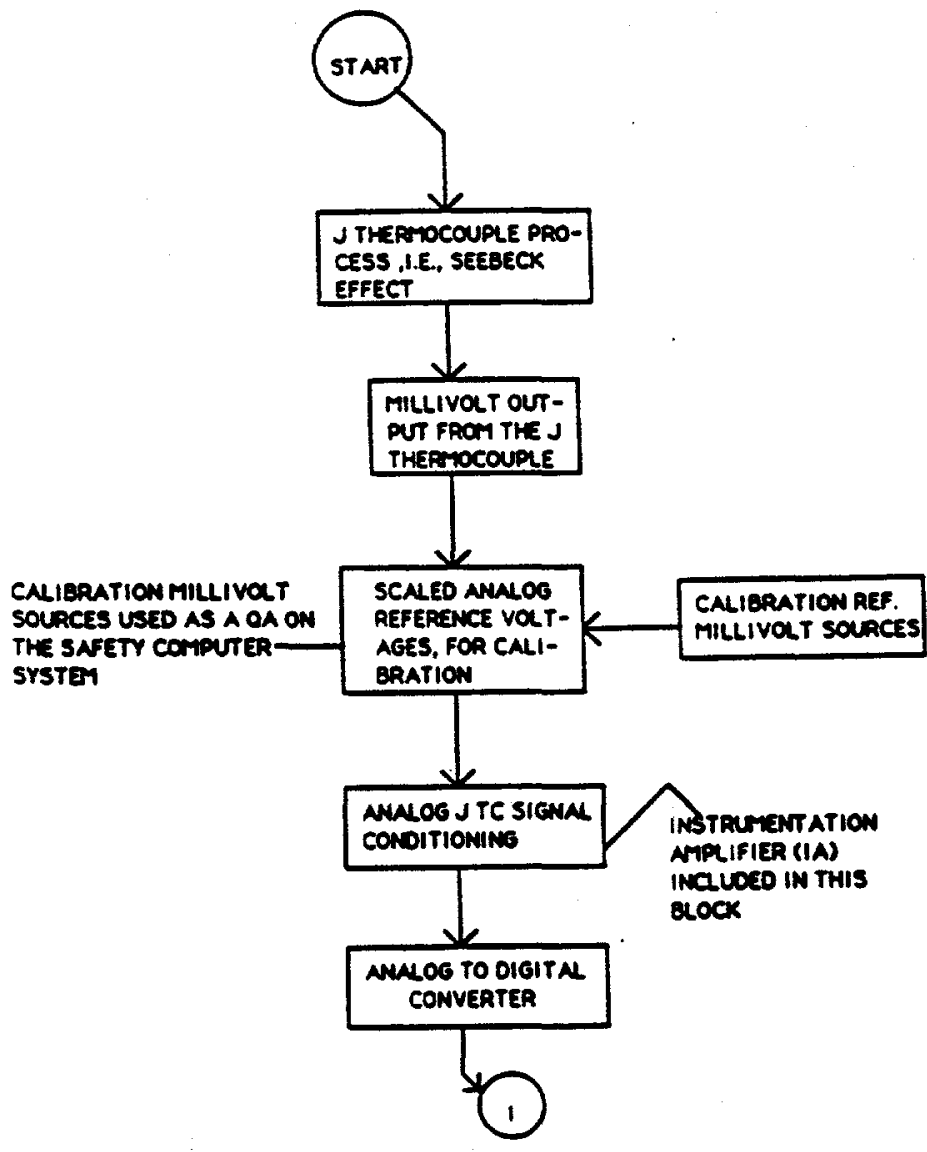

Figure D.2.1-1. DFD For The Actual Process to Determine the MP Temperature. 




Figure D.2.1-1. DFD For The Actual Process to Determine the MP Temperature (Continued). 


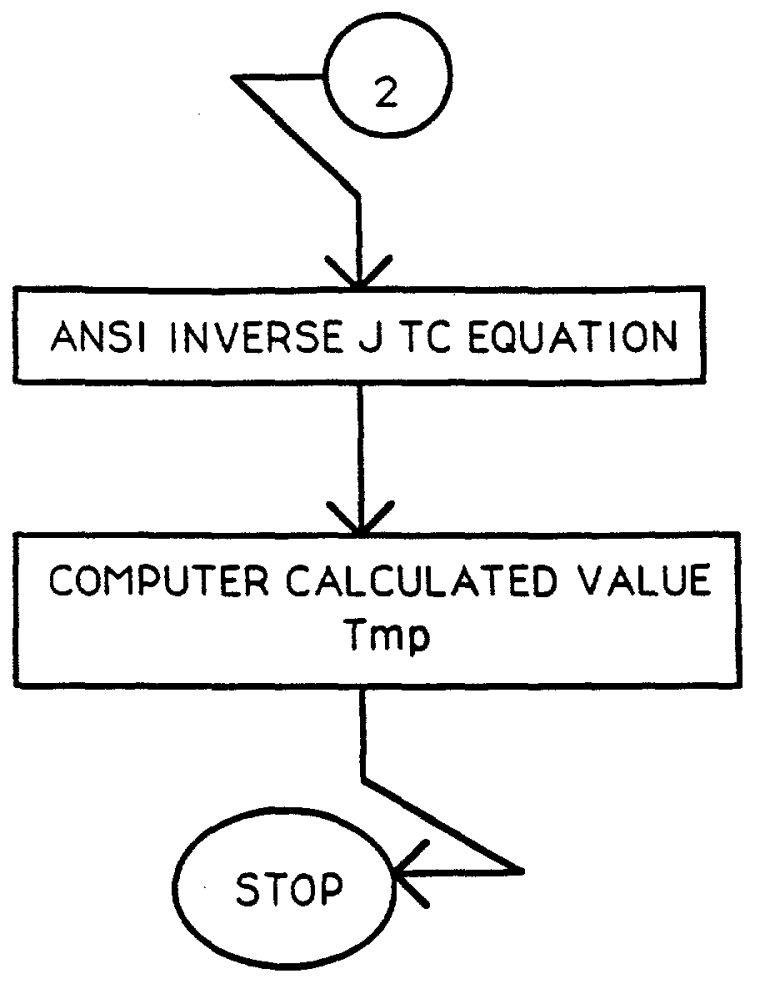

Figure D.2.1-1. DFD For The Actual Process to Determine the MP Temperanure (Continued). 


\section{D.2.2 Data Flow Diagram Simulation of The MiP Temperature Process}

The DFD for the simulation of the MP temperature process is depicted below.

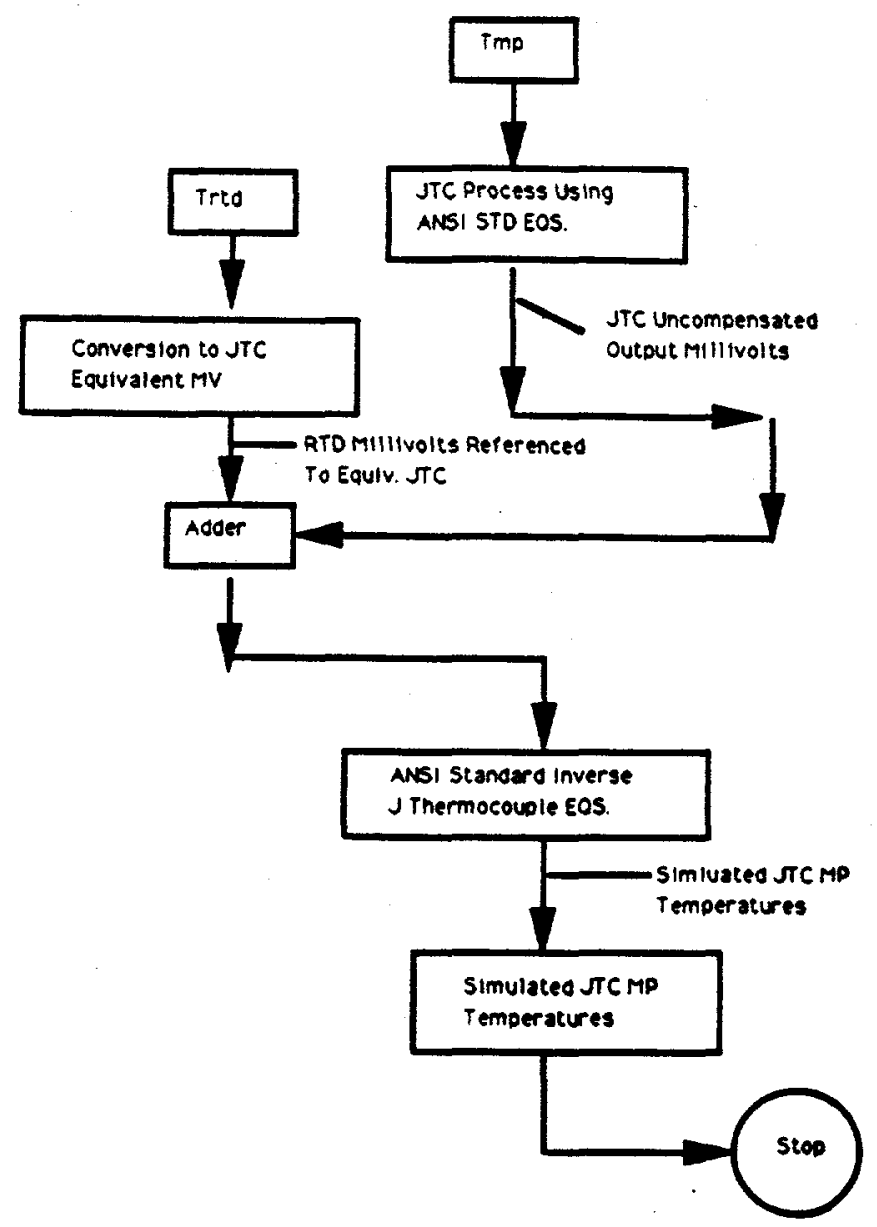

Figure D.2.2-1 DFD For the Simulation of the MP Temperature Process. 